\title{
Frailty phenotype and multi-domain impairments in older patients with chronic kidney disease
}

Simone Vettoretti ${ }^{1 *}$ (D, Lara Caldiroli ${ }^{1,2}$, Giulia Porata ${ }^{1,2}$, Carlotta Vezza $^{2}$, Matteo Cesari ${ }^{2,3}$ and Piergiorgio Messa ${ }^{1,2}$

\begin{abstract}
Background: Older subjects with chronic kidney disease (CKD) are often affected by multiple geriatric impairments that may benefit from a comprehensive geriatric assessment (CGA). However, ordinary execution of CGA in all these individuals would be unaffordable. We evaluated if Frailty Phenotype (FP) could identify older CKD-patients that may benefit the most from a CGA.

Methods: We evaluated 112 CKD patients not yet on dialysis (age $\geq 65$ years, eGFR $<45 \mathrm{ml} / \mathrm{min}$ ). FP was defined according to the criteria proposed by Fried and co-authors. CGA evaluated four domains (nutrition, physical performance, cognition and depression). Malnutrition was defined in accordance to Malnutrition-Inflammation Score (MIS) and/or by the presence of Protein Energy Wasting syndrome (PEW). Physical performance was evaluated using Short Physical Performance Battery (SPPB) and handgrip strength. Cognitive status was assessed by using Mini Mental State Examination (MMSE) and Clock Drawing Test. Mood was investigated with Geriatric Depression Scale (GDS).

Results: Average age of our cohort was $80 \pm 6$ years and mean eGFR $24 \pm 11 \mathrm{ml} / \mathrm{min} / 1.73 \mathrm{~m}^{2}$. Prevalence of frailty was $45 \%$. Frail patients (F-CKD) had higher prevalence of malnutrition (58 vs 29\%, $p=0.0005$ ), physical impairment (100\% vs 78\%; $p<0.0001$ ), cognitive dysfunction ( $83 \%$ vs 37\%; $p<0.0001)$ and depression (50\% vs $21 \% ; p<0.001)$ compared to robust ones (NF-CKD).

Moreover, F-CKD patients had higher probability to have $>2$ impaired domains ( $83 \%$ sensitivity and $76 \%$ specificity) respect to NF-CKD individuals.
\end{abstract}

Conclusions: FP is a reliable screening tool to identify older CKD-patients that may benefit from a CGA.

Keywords: Frailty phenotype, Comprehensive geriatric assessment, Chronic kidney disease, Malnutrition, Physical performance

\footnotetext{
* Correspondence: simone.vettoretti@policlinico.mi.it

'Unit of Nephrology, Dialysis and Kidney Transplantation Fondazione IRCCS

Ca' Granda Ospedale Maggiore Policlinico di Milano, Via della Commenda 15,

20122 Milan, Italy

Full list of author information is available at the end of the article
}

(c) The Author(s). 2020 Open Access This article is licensed under a Creative Commons Attribution 4.0 International License, which permits use, sharing, adaptation, distribution and reproduction in any medium or format, as long as you give appropriate credit to the original author(s) and the source, provide a link to the Creative Commons licence, and indicate if changes were made. The images or other third party material in this article are included in the article's Creative Commons licence, unless indicated otherwise in a credit line to the material. If material is not included in the article's Creative Commons licence and your intended use is not permitted by statutory regulation or exceeds the permitted use, you will need to obtain permission directly from the copyright holder. To view a copy of this licence, visit http://creativecommons.org/licenses/by/4.0/ The Creative Commons Public Domain Dedication waiver (http://creativecommons.org/publicdomain/zero/1.0/) applies to the data made available in this article, unless otherwise stated in a credit line to the data. 


\section{Background}

A growing proportion of patients with chronic kidney disease (CKD) is affected by the peculiar impairments of the geriatric age (i.e. malnutrition, sarcopenia, physical and cognitive impairments [1]). All these conditions worsen the quality of life and the overall prognosis of older patients with CKD. In those patients, the adoption of multi-disciplinary care programs may confer general health and survival benefits $[2,3]$. However, the increasing prevalence of older CKD-patients makes the ordinary execution of comprehensive geriatric assessment of all these subjects unaffordable.

Frailty is a clinical construct that describes a state of decline and vulnerability associated with a worse prognosis in terms of quality of life, prevalence of disability and survival [4]. In patients with CKD frailty is a prevalent condition (14-88\% depending on study group characteristics and frailty definitions that were used) [5-7] .

Frail CKD-patients are frequently affected by multidomain impairments [7]. Therefore, the assessment of frailty may represent a reliable tool to individuate older CKD-patients that deserve to be addressed to a comprehensive geriatric assessment since they might benefit the most from a multidisciplinary care program.

Until now there is no gold standard to diagnose frailty in CKD patients [7-9]. Frailty Phenotype (FP) [10] is a clinical tool that is easy to perform in the outpatients setting on a large scale and it has been extensively validated in CKD-patients [7, 11-13] .

We evaluated cross-sectionally the association of FP with: malnutrition, physical impairment, cognitive dysfunction and depression in older outpatients with advanced CKD. Moreover, we tested whether FP can be used as a screening tool to individuate CKD-patients to be addressed to a comprehensive geriatric assessment. Therefore, the primary endpoint of the study was to evaluate the sensitivity and specificity of FP to identify those subjects that were affected by more than one or two geriatric impairments.

\section{Methods}

\section{Patients characteristics and study design}

We evaluated 112 patients attending our outpatient clinic for advanced CKD between 9/2016 and 3/2018 (belonging to the population included in the PROVE study that has already been described elsewhere [14]). We asked to participate to the study to all eligible patients that attended the clinic during the enrollment period, when they came for a control visit. The study had a cross sectional design.

Patients were selected according to the following criteria: age $\geq 65$ years old, CKD stages $3 \mathrm{~b}$ to 5 not yet on renal replacement therapy and relatively stable eGFR over the previous 6 months (with less than $2 \mathrm{ml} / \mathrm{min} /$ $1.73 \mathrm{~m}^{2}$ of variation). In order to exclude patients that were unable to fulfill the tasks of the study protocol or whose impairment was mostly determined by the severity of a single concomitant disease, we applied some exclusion criteria that have been reported elsewhere [14]. We determined estimated glomerular filtration rate (eGFR) by CKD-EPI formula [15, 16].

Medical, biochemical and anthropometrical evaluations were collected in a unique visit that was performed in the morning after an overnight fast of at least $12 \mathrm{~h}$.

All patients signed an informed consent to participate to the study (see above "Ethics approval and consent to participate").

\section{Assessment of frailty}

Frailty was assessed by using the Frailty Phenotype (FP) as it was originally proposed by Fried and co-workers [10]. Frailty was defined by investigating the following items: unintentional weight loss, exhaustion, weakness, slow gait speed and low physical activity. Patients with three or more deranged items have been classified as frail.

In our cohort, we defined the domains of frailty as follows: 1) unwanted weight loss ( $\geq 4.5 \mathrm{~kg}$ of body mass in 12 months); 2) exhaustion (tired $\geq 4$ days per week for more than 3 months); 3) weakness (handgrip strength $<16 \mathrm{~kg}$ in females and $<27 \mathrm{~kg}$ in males); 4) slowness $(4 \mathrm{~m}$ course gait test speed $>0.8 \mathrm{~m} / \mathrm{sec}$ ); reduced physical activity (a score $<7$ at physical activity scale, that is extensively described below in the physical performance section).

\section{Nutritional intake, body composition and nutritional status}

Daily dietary protein intake was estimated by assessing normalized protein catabolic rate (nPCR). In order to guarantee the accuracy of $24 \mathrm{~h}$ urinary collection all patients were given written instructions [17]. Furthermore, we measured $24 \mathrm{~h}$ creatinine excretion on the same urine sample. Low protein diet was defined as a nPCR of $0,6-0,8 \mathrm{~g} / 24 \mathrm{~h}$.

We measured: body weight, height, body mass index (BMI, calculated according to Quetelet Index $\left(\mathrm{kg} / \mathrm{m}^{2}\right)$ ) and mid-arm muscle circumference (MAMC) of the dominant arm [14].

Body composition was analyzed with a multifrequency bioelectrical impedance analysis device (BCM, Fresenius Medical Care, Bad Homburg, Germany). We estimated: lean tissue (LT), fat tissue (FT) and over-hydration $(\mathrm{OH})$. For technical reasons data regarding body composition are available only for 84 patients.

Malnutrition was defined in accordance to the presence of Protein Energy Wasting syndrome (PEW) and/ or by individual Malnutrition-Inflammation Score (MIS).

PEW was defined according to the criteria indicated by the International Society of Renal Nutrition and 
Metabolism [18]. Malnutrition was defined as MIS $>7$ as it was previously reported in patients with CKD [19].

\section{Physical performance}

Short physical performance battery (SPPB) evaluates: the capability of maintaining standing balance, walking speed and leg strength by five repetitive chair-stands [20]. Physical performance was considered impaired when SPPB score was $<10$ [21].

Handgrip strength was measured with Jamar dynamometer (Sammons Preston Inc., Bolingbrook, IL). Impaired handgrip strength was defined by the following thresholds: $<16 \mathrm{~kg}$ in females and $<27 \mathrm{~kg}$ in males [10].

The ability to execute Instrumental Activities of Daily Life (IADL) was assessed by using Lawton and Brody's scale with normal scoring ranges of $0-8$ in women and $0-5$ in men [22].

Physical Activity Scale (PAS) is designed to assess the degree of physical activity of CKD patients aged $\geq 65$ years and a score $<7$ corresponds to reduced overall physical activity [14]. PAS $<7$ was used to define the reduction of physical activity in the assessment of $\mathrm{FP}$ score.

\section{Assessment of cognitive impairment and depression}

Cognitive status was assessed by using Mini Mental State Examination (MMSE) and Clock Drawing Test.

Mini Mental State Examination (MMSE) is an 11question measure that tests five areas of cognitive function: orientation, registration, attention and calculation, recall, and language. The maximum score is 30 . A score $\leq 23$ is indicative of cognitive impairment [23].

Clock Drawing Test is used for screening for cognitive impairment and dementia and as a measure of spatial dysfunction and neglect. The subject is presented with a circular contour and is expected to draw in the numbers on the clock face. Then the subject is asked to draw the hands at a fixed time, 10 min past 11:00). Doing the test requires verbal understanding, memory and spatially coded knowledge in addition to constructive skills [24]. A score $<5$ was considered as impaired.

Mood was investigated by using Geriatric Depression Scale (GDS) and a score $\geq 11$ was considered indicative of depression [25].

\section{Biochemical parameters}

Biochemical analyses were all executed at the central laboratory of our Institution.

\section{Domains}

In order to quantify individual geriatric impairment, we considered four domains: nutritional status, physical performance, cognitive function and depression (Fig. 1).

Malnutrition was defined by the presence of PEW and/or by a MIS $>7$.

Impaired physical performance was defined by reduced handgrip strength and/or SPPB score $<10$.

Cognitive impairment was defined by reduced MMSE score and/or pathological clock test.

Depression was defined by GDS score $\geq 11$.

The primary endpoint was to evaluate the sensitivity and specificity of FP to identify those subjects that were affected by $>1$ or $>2$ impaired domains.

\section{Statistical analysis}

All data are expressed as mean \pm SD or median \pm IQR as appropriate. Comparison of normally distributed variables was done using Student's t-test while the comparison of not normally distributed ones was done using the MannWhitney "U" test. Proportions and categorical variables were compared using the independent chi-squared $(x 2)$ test or the Fisher's exact test. We determined: sensitivity, specificity, positive and negative predictive value of FP to identify patients with $>1$ or $>2$ impaired domains. In order to estimate the strength of the association between $\mathrm{FP}$ and multi-domain impairments we calculated the Odds Ratios of these associations. Statistical analysis was carried out with Statview software version 5.0.1.

\begin{tabular}{|c|c|}
\hline $\begin{array}{l}\text { A. Nutrition: } \\
\text { Protein Energy Wasting Syndrome (PEW) } \\
\text { Malnutrition Inflammation Score (MIS) }\end{array}$ & $\begin{array}{l}\text { B. Physical performance: } \\
\text { Short Physical Performance Battery (SPPB) } \\
\text { Handgrip strenght (Jamal dynamometer) }\end{array}$ \\
\hline $\begin{array}{l}\text { C. Cognition: } \\
\text { Mini Mental State Examination (MMSE) } \\
\text { Clock Drowing Test }\end{array}$ & $\begin{array}{l}\text { D. Mood: } \\
\text { Geriatric depression scale (GDS) }\end{array}$ \\
\hline
\end{tabular}

Fig. 1 Geriatric Assessment Tools. We adopted a geriatric assessment based on four domains (a-d). A domain has been judged impaired when at least one of the tools that were used to evaluated it gave a positive result (i.e. the patient had positive PEW test than the nutritional domain was impaired). The cut-offs adopted to define the positivity of the single test are reported in the methods section. Multidomain impairment was defined by altered tests in more than one domain (i.e. having an impairment in 2 domains meant having a positive test in A plus B) 


\section{Results}

Baseline characteristics of the sample

Patients' general characteristics are reported in Table 1. Mean age was $80 \pm 6,70 \%$ were male, $56 \%$ had diabetes, $55 \%$ had previous cardiovascular (CV) events. Prevalence of frailty was $50 / 112(45 \%)$. Of note, although the majority of NF-CKD were males, F-CKD patients were equally distributed between the two sexes.

F-CKD had lower creatinine clearance than NF-CKD (creatinine clearance: $23 \pm 13 \mathrm{ml} / \mathrm{min} / 1.73$ vs $29 \pm 1415$ $\mathrm{ml} / \mathrm{min} / 1.73 \mathrm{~m}^{2} ; p=0.025$ ) and lower hemoglobin levels (hemoglobin: $\quad 12.0 \pm 1.3 \mathrm{~g} / \mathrm{dl} \quad$ vs $\quad 12.6 \pm 1.3 \mathrm{~g} / \mathrm{dl} ; \quad p=$ 0.012).

\section{Domains evaluation}

\section{Nutritional parameters, inflammation and body composition}

Nutritional parameters are shown in Table 2. F-CKD patients had lower albumin and prealbumin levels (Albu$\min 4.0 \pm 0.3 \mathrm{~g} / \mathrm{dl}$ vs $4.1 \pm 0.3 \mathrm{~g} / \mathrm{dl}, p=0.04$; Prealbumin: $25.8 \pm 5.1 \mathrm{mg} / \mathrm{dl}$ vs $29.3 \pm 5.4 \mathrm{mg} / \mathrm{dl}, p=0.037)$, but there were not significant differences in total cholesterol, transferrin, and $(25 \mathrm{OH})$ vitamin D levels. Inflammatory status of the two populations was the same as shown by CRP values (CRP: $0.46 \pm 0.72$ vs $0.46 \pm 0.79, p=0.98$ ). The proportion of patients that were prescribed a hypoproteic diet was the same in F-CKD and NF-CKD (35 vs $38 \%$ respectively) and estimated protein intake did not differ in the two groups (nPCR: $723 \pm 206$ vs $787 \pm 240$ $\mathrm{mg} / \mathrm{kg} / 24 \mathrm{~h}, p=0.13)$.

F-CKD had less lean tissue and more fat than NFCKD (lean tissue: $43 \pm 10$ vs $52 \pm 11 \%, p<0.001$; fat tissue: $39 \pm 8$ vs $33 \pm 9 \%, p<0.001)$, although there were no differences in BMI and MAMC (BMI: $28.3 \pm 5.5$ vs $27.7 \pm 4.2, p=0.52$; MAMC: $24 \pm 3 \mathrm{~cm}^{2}$ vs $25 \pm 3 \mathrm{~cm}^{2}$, $p=0.1$.

F-CKD were more malnourished at MIS (46\% vs $11 \%$, $p<0.001)$ and had higher prevalence of PEW (38\% vs $21 \%, p=0.047$ ) than NF-CKD (Table 2).

\section{Physical performance}

F-CKD had worse physical performance than NF-CKD, as demonstrated by lower average scores at SPPB and by reduced handgrip strength and PAS (Table 3). Furthermore F-CKD had higher prevalence of: impaired SPPB (100\% vs $53 \%, p<0.001)$, reduced handgrip strength ( $90 \%$ vs $58 \%, p<0.001)$ and reduced PAS $(70 \%$ vs $35 \%$, $p<0.001)$. Of note, IADL score showed no differences between the F-CKD and NF-CKD (Table 3).

\section{Cognitive and mood evaluation}

The two groups showed a significant difference in cognitive evaluation (Table 4). F-CKD patients had worse MMSE $(25.3 \pm 3.7$ vs $27.3 \pm 2.4 ; p<0,001)$ and Clock test score $(2.3 \pm 1.9$ vs $4.0 \pm 1.7 ; p<0,001)$ than NF-CKD individuals. Twenty-two percent of F-CKD had impaired MMSE and $83 \%$ had an impaired clock test vs respectively 6 and 35\% of NF-CKD (MMSE: $p=0.016$; Clock test: $p<$ $0.001)$. F-CKD had higher GDS score $(11.4 \pm 5.7$ vs $7.5 \pm$ 5.8; $p<0.001$, Table 4). Depression was more prevalent in F-CKD than in NF-CKD (50 vs $21 \%, p<0.001$; Fig. 2 ).

\section{Frailty and single/multi-domain impairments}

F-CKD patients had higher prevalence of impairments in each of the domains that were considered (Fig. 2). F-CKD patients had also a higher prevalence of multidomain impairments (Fig. 3). Indeed, FP identified CKD-patients with more than one geriatric impairment with a sensitivity of 66\% (CI95\%: $55-77$ ) and a specificity of $85 \%$ (CI95\%: 74-96), positive predictive value $88 \%$ (CI95\%: 83-93), negative predictive value 56\% (CI95\%: 50-62). Moreover, FP was even more reliable in identifying those patients that had more than two geriatric impairments: sensitivity of 83\% (CI95\%: 71-95), specificity 76\% (C195\%: 66-86), positive predictive value $89 \%$ (CI95\%: $85-93$ ), negative predictive value 66\% (CI95\%: 59-73). Overall F-CKD patients were more likely to have more than one (OR 9.51; CI95\%: 3.53-25.58) ore more than two impaired domains (15.25; CI95\%: 5.72-40.65).

Table 1 Cohort Characteristics

\begin{tabular}{|c|c|c|c|c|}
\hline & $\begin{array}{l}\text { Overall cohort } \\
n=112\end{array}$ & $\begin{array}{l}\text { NF-CKD } \\
n=62(55 \%)\end{array}$ & $\begin{array}{l}\text { F-CKD } \\
n=50(45 \%)\end{array}$ & $P$ \\
\hline Age, yrs & $80 \pm 6$ & $79 \pm 6$ & $81 \pm 6$ & 0.08 \\
\hline Males, \% & 70 & 87 & 48 & $<0.001$ \\
\hline Diabetes, \% & 56 & 58 & 54 & 0.67 \\
\hline Previous cardiovascular events, \% & 55 & 52 & 60 & 0.38 \\
\hline eGFR, $\mathrm{ml} / \mathrm{min} / 1,73 \mathrm{~m}^{2}$ & $24 \pm 11$ & $25 \pm 11$ & $24 \pm 10$ & 0.48 \\
\hline Creatinine clearance, $\mathrm{ml} / \mathrm{min} / 1,73 \mathrm{~m}^{2}$ & $27 \pm 14$ & $29 \pm 14$ & $23 \pm 13$ & 0.025 \\
\hline Urea, mg/dl & $101 \pm 35$ & $99 \pm 33$ & $103 \pm 37$ & 0.59 \\
\hline Hemoglobin, gr/dl & $12.3 \pm 1.3$ & $12.6 \pm 1.3$ & $12.0 \pm 1.3$ & 0.012 \\
\hline
\end{tabular}

Data are expressed as number (\%) or mean \pm standard deviation for continuous variables 
Table 2 Nutritional Status

\begin{tabular}{|c|c|c|c|c|}
\hline & $\begin{array}{l}\text { Overall cohort } \\
n=112\end{array}$ & $\begin{array}{l}\text { NF-CKD } \\
n=62(55 \%)\end{array}$ & $\begin{array}{l}\text { F-CKD } \\
n=50(45 \%)\end{array}$ & $P$ \\
\hline \multicolumn{5}{|l|}{ Nutritional Parameters } \\
\hline Albumin, gr/dl & $4.0 \pm 0.3$ & $4.1 \pm 0.3$ & $4.0 \pm 0.3$ & 0.04 \\
\hline Prealbumin, mg/dl & $28.3 \pm 5.4$ & $29.3 \pm 5.4$ & $25.8 \pm 5.1$ & 0.037 \\
\hline Total cholesterol, mg/dl & $167 \pm 37$ & $163 \pm 31$ & $171 \pm 44$ & 0.28 \\
\hline Transferrin, mg/dl & $230 \pm 40$ & $229 \pm 39$ & $233 \pm 41$ & 0.62 \\
\hline Vitamin D (25OH), ng/ml & $29 \pm 17$ & $30 \pm 15$ & $28 \pm 19$ & 0.57 \\
\hline CRP, mg/dl & $0.46 \pm 0.75$ & $0.46 \pm 0.79$ & $0.46 \pm 0.72$ & 0.98 \\
\hline $\mathrm{nPCR}, \mathrm{mg} / \mathrm{kg} / 24 \mathrm{~h}$ & $758 \pm 227$ & $787 \pm 240$ & $723 \pm 206$ & 0.13 \\
\hline Hypoproteic diet, \% & 37 & 38 & 35 & 0.76 \\
\hline \multicolumn{5}{|l|}{ Body Composition $^{a}$} \\
\hline $\mathrm{BMI}, \mathrm{kg} / \mathrm{m} 2$ & $28.0 \pm 4.8$ & $27.7 \pm 4.2$ & $28.3 \pm 5.5$ & 0.52 \\
\hline MAMC, $\mathrm{cm} 2$ & $25 \pm 3$ & $25 \pm 3$ & $24 \pm 3$ & 0.10 \\
\hline \multicolumn{5}{|l|}{ Bio-impedentiometry results } \\
\hline Lean tissue, \% & $48 \pm 12$ & $52 \pm 11$ & $43 \pm 10$ & $<0.001$ \\
\hline Fat tissue, \% & $35 \pm 9$ & $33 \pm 9$ & $39 \pm 8$ & $<0.001$ \\
\hline Lean tissue/fat tissue ratio & $1.60 \pm 0.98$ & $1.84 \pm 1.09$ & $1.22 \pm 0.61$ & 0.004 \\
\hline Over Hydration, L & $1.3 \pm 1.7$ & $1.2 \pm 1.8$ & $1.5 \pm 1.5$ & 0.44 \\
\hline \multicolumn{5}{|l|}{ Malnutrition } \\
\hline PEW, \% & 29 & 21 & 38 & 0.047 \\
\hline MIS > 7\% & 27 & 11 & 46 & $<0.001$ \\
\hline
\end{tabular}

\section{Discussion}

Among older CKD-patients FP has a prevalence of $45 \%$ and it is associated with higher prevalence of malnutrition, reduced physical performance, cognitive and mood impairments. Our results suggest also that FP may be used to identify older CKD-patients that are affected by multiple geriatric impairments and that may therefore benefit the most of a comprehensive geriatric assessment.

In previous studies performed in CKD populations prevalence of frailty ranged from 16 to $88 \%$ depending on the methods and the definitions that were adopted $[7,11-13,26-29]$. This variability depends on the fact that the definitions used to identify frailty are pretty variegated and take in account different clinical and functional aspects.

Van Loon and co-authors compared the performances of several tools designed to assess the presence of frailty in a population of older CKD-patients that were incident on dialysis [7]. They concluded that all these tools lacked of the discriminating abilities that were necessary to rule

Table 3 Physical Performance

\begin{tabular}{|c|c|c|c|c|}
\hline & $\begin{array}{l}\text { Overall cohort } \\
n=112\end{array}$ & $\begin{array}{l}\text { NF-CKD } \\
n=62(55 \%)\end{array}$ & $\begin{array}{l}\text { F-CKD } \\
n=50 \text { (45\%) }\end{array}$ & $P$ \\
\hline \multicolumn{5}{|l|}{ Physical Functions } \\
\hline SPPB score & $7.5 \pm 2.8$ & $9.3 \pm 1.8$ & $5.2 \pm 2.2$ & $<0.001$ \\
\hline Handgrip strength & $21.2 \pm 7.5$ & $24.8 \pm 6.8$ & $16.8 \pm 5.5$ & $<0.001$ \\
\hline IADL score & $5.0 \pm 1.6$ & $5.0 \pm 1.2$ & $4.9 \pm 2.0$ & 0.718 \\
\hline Physical activity scale & $7.0 \pm 4.0$ & $8.8 \pm 3.6$ & $5.0 \pm 3.6$ & $<0.001$ \\
\hline Impaired SPPB, \% & 74 & 53 & 100 & $<0.001$ \\
\hline Impaired handgrip strength, \% & 72 & 58 & 90 & $<0.001$ \\
\hline
\end{tabular}

Data are expressed as number (\%) or mean \pm standard deviation for continuous variables SPPB Short Physical Performance Battery, IADL Instrumental Activities of Daily Life 
Table 4 Cognitive and Mood Evaluation

\begin{tabular}{|c|c|c|c|c|}
\hline & $\begin{array}{l}\text { Overall cohort } \\
n=112\end{array}$ & $\begin{array}{l}\text { NF-CKD } \\
n=62(55 \%)\end{array}$ & $\begin{array}{l}\text { F-CKD } \\
n=50(45 \%)\end{array}$ & $P$ \\
\hline \multicolumn{5}{|l|}{ Cognitive status } \\
\hline MMSE & $26.4 \pm 3.2$ & $27.3 \pm 2.4$ & $25.3 \pm 3.7$ & $<0.001$ \\
\hline Clock test & $3.3 \pm 2.0$ & $4.0 \pm 1.7$ & $2.3 \pm 1.9$ & $<0.001$ \\
\hline Impaired MMSE, \% & 14 & 6 & 22 & 0.016 \\
\hline Impaired Clock test, \% & 56 & 35 & 83 & $<0.001$ \\
\hline \multicolumn{5}{|l|}{ Mood status } \\
\hline GDS score & $9.2 \pm 6.1$ & $7.5 \pm 5.8$ & $11.4 \pm 5.7$ & $<0.001$ \\
\hline
\end{tabular}

out frailty (defined as $>1$ geriatric impairment) when they were compared with comprehensive geriatric assessment. Although this study was conducted in patients that were starting the renal replacement therapy while ours considered patients with better renal function (i.e. eGFR: $24 \pm 11 \mathrm{ml} / \mathrm{min} / 1.73 \mathrm{~m}^{2}$ ), the results of the two studies are comparable. Both studies found that the prevalence of FP was almost $50 \%$ and they showed that FP has a specificity of $85 \%$ to exclude patients with less than two geriatric impairment. Additionally, our data demonstrate also that sensitivity and specificity of FP to individuate patients with multiple domain impairments increases in those subjects that have more than two impairments.
Although comprehensive geriatric assessment remains the best tool to evaluate frailty in older CKD- patients, it cannot be ordinarily monitored in all outpatients attending nephrology clinics since it is quite time consuming and it needs specific geriatric competences. Therefore, we suggest that comprehensive geriatric assessment should be performed only in selected individuals that have been identified as frail. Our results suggest that, beyond being an index of vulnerability, FP is a reliable screening tool to identify older CKD-patients that might benefit the most from an integrated and multidisciplinary program of care. Indeed, frailty is not a fixed or inescapable progressive condition, but there are potentially reversible contributors (i.e. poor nutritional status,

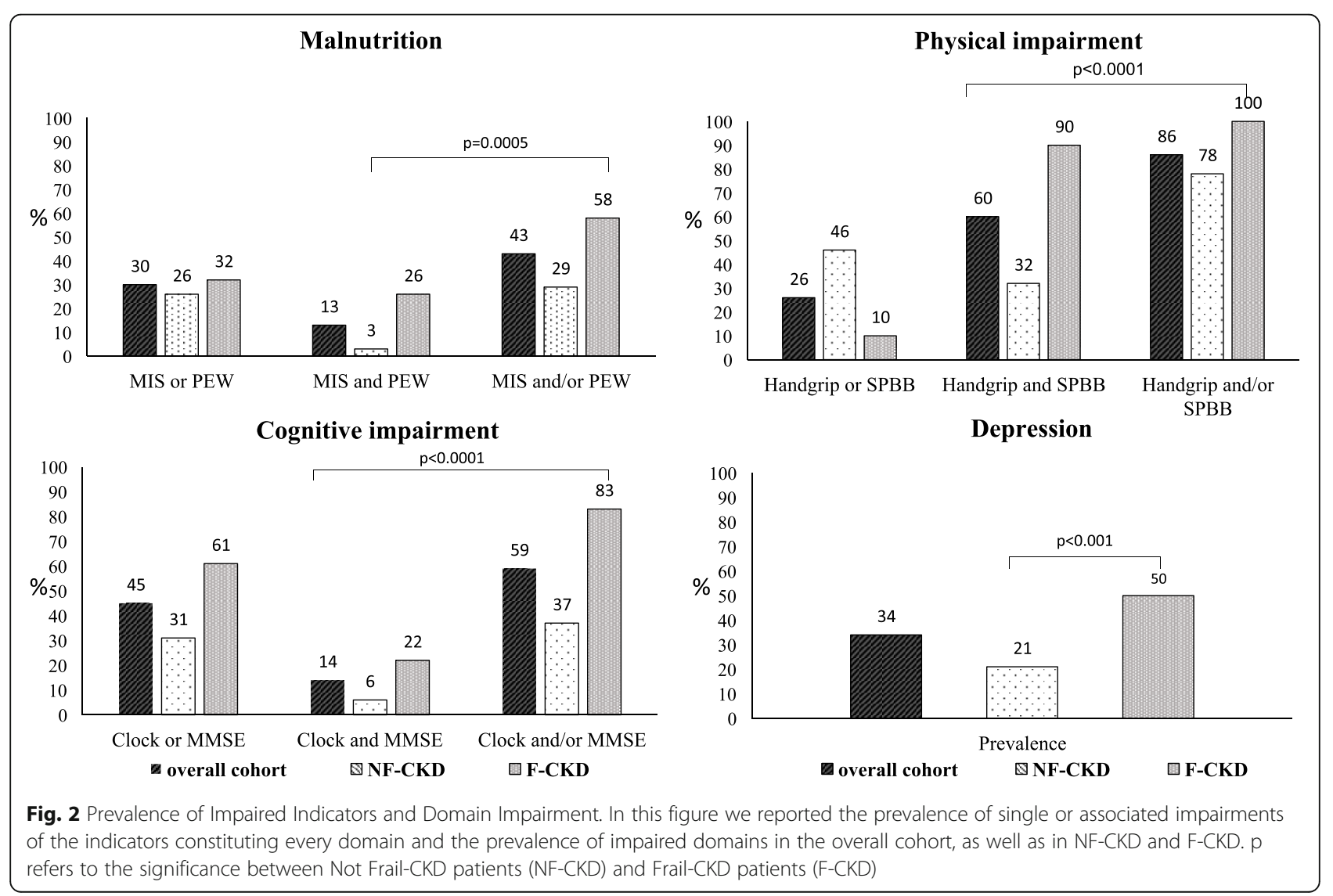




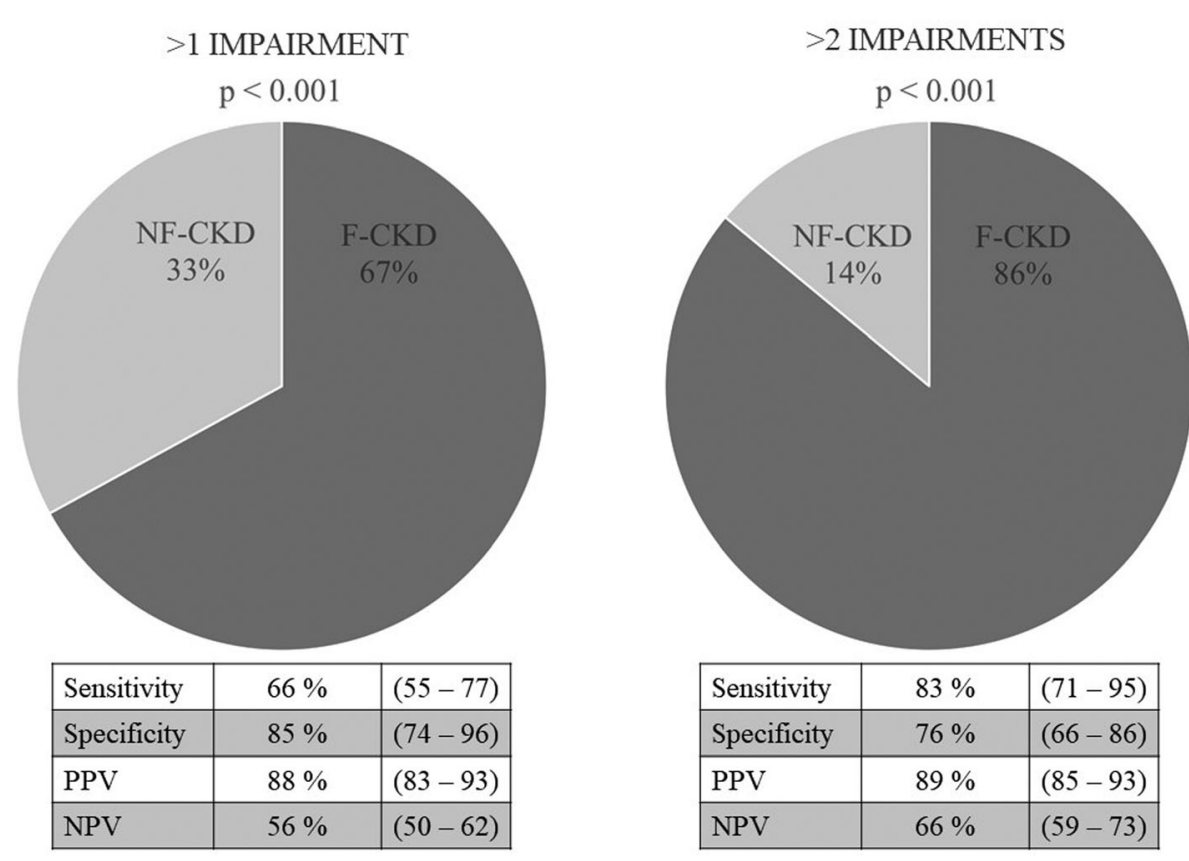

Fig. 3 Association Between Frailty and Multi-domain Impairments. Data between () express 95\% confidence interval. PPV positive predictive value, NPV negative predictive value

low mood and physical inactivity) that can be modified by multidisciplinary interventions aimed to improve patients' outcomes [30].

Our results indicate that frailty is equally prevalent in patients with advanced CKD as well as in those that are incident on dialysis. Therefore, we believe that FP should be systematically assessed in older CKD-patients, since early stages of disease, in order to early identify those that could benefit the most of a comprehensive geriatric assessment. FP is a widely validated method that is focused on physical and subjective aspects [10]. It is based on a pre-defined set of five criteria exploring the presence/absence of signs or symptoms that can easily be assessed in the outpatients setting and it does not take more than 10 min to be concluded.

Notably, although we excluded by our study all patients with previous diagnosis of depression, we found that one third of the overall cohort was actually affected by depression of clinical relevance. Since the prevalence of depression was more than doubled in F-CKD respect to NF-CKD individuals, we suggest that FP might be a reliable screening test to identify those patients that are likely to suffer of misdiagnosed depression.

Our study has some limitations. It is relatively small, even though the number of patients that were enrolled reflects the average of the other studies that were previously performed on the same topic. Furthermore, we adopted quite restrictive inclusion criteria therefore we may have excluded sickest and frailer individuals. However, by excluding those subjects whose frailty and overall outcomes depend mostly on the severity of a single disease, we aimed to focus on those patients that are frequently overlooked because of an apparently favorable prognosis. Therefore, whether we had considered all older patients attending nephrology outpatients it is possible that the actual prevalence of frailty and geriatric impairments would have been even higher than what we found.

\section{Conclusions}

To the best of our knowledge this is the first study that explores whether FP can be used as a screening tool to stratify the risk of geriatric impairment of CKD-patients in the pre-dialysis setting. Overall, we believe that our results support the clinical use of FP to identify older patients with moderate to severe CKD that may benefit the most of a comprehensive geriatric assessment.

\section{Abbreviations \\ CKD: Chronic kidney disease; FP: Fried Phenotype; NYHA: New York Herat Association; CGA: Comprehensive geriatric assessment; NF-CKD: Not frail chronic kidney disease patients; F- CKD: Frail chronic kidney disease patients; SPPB: Short physical performance battery; MAMC: Mid arm muscle area; MMSE: Mini mental state examination; MIS: Malnutrition inflammation score; IADL: Instrumental activities of daily life; PAS: Physical activity scale; \\ PEW: Protein energy wasting syndrome; GDS: Geriatric depression scale}

\section{Acknowledgements}

We gratefully thank Lucia Baiguini and Daniela Rusconi for their help in collecting and storing biological samples.

\section{Authors' contributions}

S.V., L.C. and G.P. drafted the manuscript. C.V., G.P. and L.C. followed the patients and collected and analysed the data. S.V., M.C. and P.M. contributed 
to the study concept and design. All authors participated in critically reviewing the article for important intellectual content and approved the final version of the manuscript.

\section{Funding}

This research has been supported by the research funds of Fondazione IRCC S Ca' Granda Ospedale Maggiore Policlinico di Milano and by Department of Clinical Sciences and Community Health - Università degli Studi di Milano. The funders had no role in study design, data collection and analysis, decision to publish, or preparation of the manuscript.

\section{Availability of data and materials}

The datasets analyzed in the current study are not publicly available due to the fact that they belong to a larger dataset that is shared in a research consortium involving the University Sacro Cuore of Piacenza and other Departments of the University of Milan. Therefore, some data are currently under analysis also for other research purposes. The original dataset could be provided by the corresponding author, upon the approval of the other members of the consortium, on reasonable request.

\section{Ethics approval and consent to participate}

Since the research involves human beings, all the procedures complied with the declaration of Helsinky and the study protocol was approved preliminary approved by the Ethical Committee of our Institution - Comitato Etico Milano Area 2 (approval document 347/2010). Therefore, all the participants signed an informed consent before being enrolled in the study.

\section{Consent for publication}

All authors have read the final version of the manuscript and approved its submission for publication.

\section{Competing interests}

None of the authors has any competing interests to declare.

\section{Author details}

${ }^{1}$ Unit of Nephrology, Dialysis and Kidney Transplantation Fondazione IRCCS Ca' Granda Ospedale Maggiore Policlinico di Milano, Via della Commenda 15, 20122 Milan, Italy. ${ }^{2}$ Department of Clinical Sciences and Community Health, Università degli Studi di Milano, Milan, Italy. ${ }^{3}$ Unit of Geriatrics Fondazione IRCCS Ca' Granda Ospedale Maggiore Policlinico di Milano, Milan, Italy.

Received: 9 February 2020 Accepted: 8 September 2020

Published online: 29 September 2020

\section{References}

1. Aucella F, et al. Beyond chronic kidney disease: the diagnosis of Renal Disease in the Elderly as an unmet need. A position paper endorsed by Italian Society of Nephrology (SIN) and Italian Society of Geriatrics and Gerontology (SIGG). J Nephrol. 2019. https://doi.org/10.1007/s40620-01900584-4.

2. Curtis BM, et al. The short- and long-term impact of multi-disciplinary clinics in addition to standard nephrology care on patient outcomes. Nephrol Dial Transplant. 2005. https://doi.org/10.1093/ndt/gfh585.

3. Farrington K, et al. Clinical Practice Guideline on management of older patients with chronic kidney disease stage $3 B$ or higher (EGFR $<45 \mathrm{~mL} / \mathrm{min} /$ 1.73 m2). Nephrol Dial Transplant. 2016;32:ii1-ii66.

4. Clegg A, Young J, lliffe S, Rikkert MO, Rockwood K. Frailty in elderly people. Lancet (London, England). 2013;381:752-62.

5. Ballew SH, et al. Frailty, kidney function, and Polypharmacy: the atherosclerosis risk in communities (ARIC) study. Am J Kidney Dis. 2017. https://doi.org/10.1053/j.jjkd.2016.08.034.

6. Nixon $\mathrm{AC}$, et al. Frailty and chronic kidney disease: current evidence and continuing uncertainties. Clin Kidney J. 2018. https://doi.org/10. 1093/ckj/sfx134.

7. van Loon IN, et al. Frailty screening tools for elderly patients incident to dialysis. Clin J Am Soc Nephrol. 2017. https://doi.org/10.2215/CJN.11801116.

8. Kiely DK, Cupples LA, Lipsitz LA. Validation and comparison of two frailty indexes: the MOBILIZE Boston study. J Am Geriatr Soc. 2009;57:1532-9.

9. Theou O, Brothers TD, Peña FG, Mitnitski A, Rockwood K. Identifying common characteristics of frailty across seven scales. J Am Geriatr Soc. 2014;62:901-6.
10. Fried LP, Tangen CM, Walston J, Newman AB, Hirsch C, Gottdiener J, et al. Frailty in older adults: evidence for a phenotype. J Gerontol A Biol Sci Med Sci. 2001. https://doi.org/10.1093/gerona/56.3.M146.

11. Wilhelm-Leen ER, Hall YN, Tamura MK, Chertow GM. Frailty and chronic kidney disease: the third National Health and nutrition evaluation survey. Am J Med. 2009. https://doi.org/10.1016/j.amjmed.2009.01.026.

12. Delgado C, et al. Association of Frailty based on self-reported physical function with directly measured kidney function and mortality. BMC Nephrol. 2015. https://doi.org/10.1186/s12882-015-0202-6.

13. Lee SJ, Son H, Shin SK. Influence of frailty on health-related quality of life in pre-dialysis patients with chronic kidney disease in Korea: a cross-sectional study. Health Qual Life Outcomes. 2015. https:/doi.org/ 10.1186/s12955-015-0270-0

14. Vettoretti $S$, et al. Sarcopenia is associated with malnutrition but not with systemic inflammation in older persons with advanced CKD. Nutrients. 2019; 11:1378.

15. Skali $\mathrm{H}$, et al. Prognostic assessment of estimated glomerular filtration rate by the new chronic kidney disease epidemiology collaboration equation in comparison with the modification of diet in renal disease study equation. Am Heart J. 2011. https://doi.org/10.1016/j.ahj.2011.06.006.

16. Matsushita $K$, et al. Comparison of risk prediction using the CKD-EPI equation and the MDRD study equation for estimated glomerular filtration rate. JAMA - J Am Med Assoc. 2012. https://doi.org/10.1001/jama.2012.3954.

17. Maroni BJ, Steinman TI, Mitch WE. A method for estimating nitrogen intake of patients with chronic renal failure. Kidney Int. 1985. https://doi.org/10. 1038/ki.1985.10.

18. Fouque $\mathrm{D}$, et al. A proposed nomenclature and diagnostic criteria for protein-energy wasting in acute and chronic kidney disease. Kidney Int 2008;73:391-8.

19. Kalantar-Zadeh K, Kopple JD, Block G, Humphreys MH. A malnutritioninflammation score is correlated with morbidity and mortality in maintenance hemodialysis patients. Am J Kidney Dis. 2001;38:1251-63.

20. Guralnik JM, Winograd CH. Physical performance measures in the assessment of older persons. Aging Clin Exp Res. 1994. https://doi.org/10. 1007/bf03324256.

21. Pavasini $R$, et al. Short physical performance battery and all-cause mortality: systematic review and meta-analysis. BMC Med. 2016. https://doi.org/10. 1186/s12916-016-0763-7.

22. Lawton MP, Brody EM. Assessment of older people: self-maintaining and instrumental activities of daily living. Gerontologist. 1969. https://doi.org/10. 1093/geront/9.3_Part_1.179.

23. Folstein MF, Folstein SE, McHugh PR. 'Mini-mental state'. A practical method for grading the cognitive state of patients for the clinician. J Psychiatr Res. 1975. https://doi.org/10.1016/0022-3956(75)90026-6.

24. Royall DR, Cordes JA, Polk M. CLOX: an executive clock drawing task. J Neurol Neurosurg Psychiatry. 1998. https://doi.org/10.1136/jnnp.64.5.588.

25. Parmelee PA, Katz IR, Lawton MP. Depression among institutionalized aged: assessment and prevalence estimation. J Gerontol. 1989:44:M22-9.

26. Chowdhury R, Peel NM, Krosch M, Hubbard RE. Frailty and chronic kidney disease: a systematic review. Arch Gerontol Geriatr. 2017;68:135-42.

27. Ali H, Abdelaziz T, Abdelaal F, Baharani J. Assessment of prevalence and clinical outcome of frailty in an elderly predialysis cohort using simple tools. Saudi J Kidney Dis Transplant. 2018. https://doi.org/10.4103/1319-2442.225175.

28. Pugh J, et al. Frailty and comorbidity are independent predictors of outcome in patients referred for pre-dialysis education. Clin Kidney J. 2016. https://doi.org/10.1093/ckj/sfv150.

29. Vezza C, et al. Use of the frailty index in older persons with chronic kidney disease. J Am Med Dir Assoc. 2019. https://doi.org/10.1016/j.jamda.2019.04.015.

30. Johansen $\mathrm{KL}$, et al. Factors associated with frailty and its trajectory among patients on hemodialysis. Clin J Am Soc Nephrol. 2017. https://doi.org/10. 2215/CJN.12131116.

\section{Publisher's Note}

Springer Nature remains neutral with regard to jurisdictional claims in published maps and institutional affiliations. 